hospices who are interested in developing their carers' support services and have shared the course content and experiences with them.

\section{P-249 BARRIERS AND FACILITATORS TO IMPLEMENTING THE CSNAT IN A COMMUNITY PALLIATIVE CARE SETTING}

${ }^{1,2}$ Anne Finucane, 1,2Zoe Horseman, 1,2Libby Milton. 'The University of Edinburgh, Edinburgh, UK; ${ }^{2}$ Marie Curie, Edinburgh, UK

\subsection{6/bmispcare-2017-hospice.274}

Background Family carers play a central role in communitybased palliative care. However, caring for a terminally ill person puts the carer at increased risk of physical and mental morbidity, which is detrimental for both carer and patient (Williams \& McCorkle, 2011). The validated Carer Support Needs Assessment Tool (CSNAT) provides a comprehensive measure of carer support needs and is intended for use in community palliative care (Ewing \& Grande 2013). The CSNAT creates an opportunity for carers to discuss their needs with healthcare professionals, facilitating the provision of appropriate support. A recent audit demonstrated poor use of the CSNAT in a Scottish community specialist palliative care service despite training and support.

Aims To identify barriers and facilitators to implementation of the CSNAT in a community specialist palliative care service.

Methods A qualitative study was undertaken, involving interviews with 12 palliative care nurse specialists from two community nursing teams in Lothian, Scotland. Data was audiorecorded, transcribed and thematically analysed using a framework approach.

Results Data analysis is in progress. The results will identify factors which enable and prevent the use of the CSNAT in a community palliative care setting. Recommendations for improving the acceptability of the CSNAT will be developed.

Conclusion Findings from this study have the potential to enhance engagement with the CSNAT, make it more congruent with current nursing practice, and improve the experience of carers of people approaching the end-of-life.

\section{P-250 MOMENTS TREE - CELEBRATING COMPASSION}

Tracey Taylor, Kate Nolan, Joanne Davison. Marie Curie Hospice Liverpool, UK

\subsection{6/bmispcare-2017-hospice.275}

Background Specialist palliative care is provided in a challenging environment, where professionals and volunteers often have to deal with death and dying, compassion is an integral part of the care provision. In order to look after the wellbeing of staff and volunteers, in preventing compassion fatigue there is a need to acknowledge it.

Aim(s) For individuals to share moments of compassion seen, witnessed or told about that have made a difference to another human being. Acknowledging the compassion by recognition, recording and celebrating as it deserves.

Methods Staff and volunteers were asked to reflect and record their moments which were collected and displayed on leaves. A tree transfer on the wall created a backdrop for the leaves to be displayed and shared. External senior staff were requested to nominate best team moment and best person-centred moment. The hospice team voted for their best moment.
Certificates and prizes were awarded as part of the celebration afternoon held in the hospice for all staff and volunteers.

Results Thirty-nine moments were recorded.

All departments were represented at least once. Initial feedback included:' the quotes were all inspiring'; ' it was hard to nominate one as they were all so good'; 'Thank you for the privilege of reading them all.' Everyone was a winner as each moment was unique.

Conclusions The introduction of a permanent tree that is refreshed and leaves changed with the seasons will be established. Recognition of the importance of celebrating those moments of compassion that would otherwise go unseen providing support to our hospice team.

\section{P-251 THE JOURNEY FROM A CARING HOSPICE TO A COMPASSIONATE HOSPICE}

Suzanne McArthur, Cheryl Brewerton, Sarah Wells. Marie Curie West Midlands, Solihull, UK

\subsection{6/bmjspcare-2017-hospice.276}

Background Compassion can be defined as the sensitivity to distress of self and others with a commitment to try and do something about it and prevent it. Compassionate care can positively influence staff efficiency, communication and patient and staff satisfaction by promoting person centred care. A compassionate workforce is vitally important to ensure that innovative practice and quality improvements succeed in meeting the challenges of modern healthcare (West et al., 2017). West et al. (2017) identify that compassionate leadership enhances the intrinsic motivation of staff and reinforces their fundamental values. It has been recognised that compassion within the workforce also creates a sense of safety and also develops a sense of empowerment and support. A key component of delivering compassionate care is empathy. Cole-King and Gilbert (2011) identified that a personal quality that influences someone's capacity for empathy is self-compassion.

Methods With this in mind, the leadership team at the Marie Curie Hospice, West Midlands focussed their efforts upon how best the workforce could be supported to facilitate compassionate care. A scoping exercise was carried out to build upon existing areas of good practice such as clinical supervision, morning debrief sessions for the night staff and Schwartz Rounds, and to make them robust. A gap analysis revealed that there were additional practices and skills that staff could apply to help build up their levels of self-compassion. The hospice is now working towards a weekly mindfulness session for staff, a weekly lunch time walking group, three minute mindfulness sessions before the start of meetings and the introduction of compassion circles. The latter has been adopted by other the local service providers, with the vision of developing a compassionate caring community.

\section{P-252 ACHIEVING SUCCESS THROUGH HOSPICE EDUCATION}

Rachel Chronnell, Andrew Thompson. Prospect Hospice, Swindon, UK

10.1136/bmispcare-2017-hospice.277

Background Prospect Hospice's vision is Excellence and Choice in End-of-Life Care, both through the provision of care and by influencing and enhancing the care others give through education and community engagement. Education has 
been a key strand of Prospect Hospice's work for more than a decade and, more recently, the hospice's Board of Trustees have sought recognition for the excellence of the standard of education and training offered there.

Aims Specifically, the Board of Trustees felt strongly that the education team should offer accredited courses, and achieve external recognition for the standard of our education offering.

Methods A new role of Education Manager was created to supplement the Education Facilitator and Administrator in the team. This role was recruited to swiftly, and the new manager approached a range of accreditation bodies, from which the NCFE was chosen. NCFE had recognised that Prospect Hospice had limited resources as a charity whose funding was predominantly raised through the local community. The Education Manager then compiled a 'centre folder' of policies and procedures to demonstrate high standards of teaching and quality assurance at Prospect Hospice.

Concurrently the Education Manager looked into the Skills for Health (SfH) Quality Mark scheme, creating a portfolio of evidence to demonstrate outstanding delivery of learning and training from the education team to support a highly motivated and effective workforce. Following the submission of this, two $\mathrm{SfH}$ assessors reviewed paperwork, interviewed trainers and learners and observed teaching to benchmark Prospect Hospice's standards with their own.

Results In August 2016 Prospect Hospice became an approved NCFE education and training centre for its courses. In March 2017 Prospect Hospice became the first fully independent hospice to achieve the Skills for Health Quality Mark. These results were achieved within nine months of the Board of Trustees' request.

\section{P-253 EDUCATOR AMNESTY! DEVELOPMENT OF A NETWORK SPECIALIST PALLIATIVE CARE EDUCATOR DEVELOPMENT PROGRAMME}

\begin{abstract}
1,2Karen Groves, ${ }^{2,3}$ Salli Jeynes, ${ }^{4}$ Sharon Phillips, ${ }^{3}$ Vanessa Shaw, ${ }^{5,6}$ Jan Howard, ${ }^{1}$ Cathy Godfrey. 'Queenscourt Hospice, Southport, UK; ${ }^{2}$ Cheshire and Merseyside Palliative and End of LIfe Care Network, UK; ${ }^{3}$ End of Life Care Partnership, Cheshire, UK; ${ }^{4}$ Marie Curie Palliative Care Institute, Liverpool, UK; ${ }^{5}$ Queenscourt Hospice, Southport, UK; ${ }^{6}$ Liverpool Marie Curie Institute, UK
\end{abstract}

\subsection{6/bmjspcare-2017-hospice.278}

Background In 2014, 322 specialist palliative care (SPC) professionals responded to a network education strategy group (ESG) workforce scoping exercise. The majority spent at least $10 \%-20 \%$ of their time educating, $70 \%$ in clinical front-facing areas or at point of care, rather than from, or in, education centres, providing academic courses or online learning. Preparation for educating experienced by the majority was observation/experience $(12 \%)$ or ENB 998 course, single module or Train the Trainer courses (30\%-40\%). Less than 10\% had educational qualifications.

Approach Six main challenges for educators were identified educating peers and those perceived to be higher in professional hierarchy; managing personalities; lack of knowledge of best practice in supporting adult learning; cultural differences; developing by teaching with others; lack of peer review. A successful bid for Multiprofessional Training and Education Monies (MPET) funded the three education centres to design, develop and deliver the programme, for three cohorts each, over a two year period, and an independent research evaluation.

Results Educators from across the network worked together to develop a bespoke Educator Development Programme (EDP) to address the expressed needs and challenges of all (273) SPC professionals who did not already have educational qualifications or a development pathway in place and yet may have been teaching as part of their role, for a number of years. Doctors were excluded as separate funded mechanisms are already in place for formally training and recognising medical teachers.

Conclusions EDP was designed as three modules, addressing each of 'one to one', 'small group' and 'formal' teaching; delivered over a period of one year to allow time for practice, reflection, peer review and mentorship; to increase knowledge, skills and confidence. This poster describes the development process and design.

\section{P-254 EMBEDDING THE CARE CERTIFICATE INTO CLINICAL APPRENTICESHIPS}

Mandy Motley, Donna Walker. LOROS Hospice, Leicester, UK

\subsection{6/bmjspcare-2017-hospice.279}

Background Following the Francis Review, Camilla Cavendish carried out a review of support workers and health care assistants across health and social care. Her recommendations formed the basis of the Care Certificate which was formally launched on 1 April 2015, and required all new health care assistant and social care staff to achieve the Care Certificate in 12 weeks of commencing employment. At LOROS we introduced a new post into the organisation, Assistant Practitioner (AP), to support the development of the non-registered staff and to lead the implementation of the care certificate across the hospice.

Aims Our aim was to develop a robust programme which not only ensured new healthcare assistants achieved the Care Certificate, but also provided valid evidence to support those staff who were also undertaking a healthcare apprenticeship.

Methods A programme of training and education has been developed which ensures all knowledge and skills required for their role are covered. This entails a presentation for all of the 15 standards with resources drawn from both the Skills for Health website and organisational specific information. The AP has completed the CAVA award which enabled her to ensure the assessment of the student work covered the learning outcomes for both the care certificate and the apprenticeship diploma. There is regular partnership working between the AP and the assessor from college, including joint standardisation meetings.

Results All new healthcare assistants achieve their care certificate in a timely fashion, and those on an apprenticeship are able to map the evidence for up to $30 \%$ of their diploma. Apprentices who have achieved their apprenticeships have secured permanent employment at the hospice.

Conclusion The dedicated role within the organisation to support this initiative with an appropriately qualified member of staff, working closely with the college has ensured the success of this approach. 